\title{
MODELING AND SIMULATION OF LONGWALL SCRAPER CONVEYOR CONSIDERING OPERATIONAL FAULTS
}

\author{
KRZYSZTOF CENACEWICZ, ANDRZEJ KATUNIN \\ Silesian University of Technology, Faculty of Mechanical Engineering, Institute of Fundamentals of Machinery Design, \\ e-mail: cenacewicz@o2.pl; andrzej.katunin@polsl.pl
}

\begin{abstract}
The paper provides a description of analytical model of a longwall scraper conveyor, including its electrical, mechanical, measurement and control actuating systems, as well as presentation of its implementation in the form of computer simulator in the $\mathrm{Matlab}^{\circledR} / \mathrm{Simulink}^{\circledR}$ environment. Using this simulator eight scenarios typical of usual operational conditions of an underground scraper conveyor can be generated. Moreover, the simulator provides a possibility of modeling various operational faults and taking into consideration a measurement noise generated by transducers. The analysis of various combinations of scenarios of operation and faults with description is presented. The simulator developed may find potential application in benchmarking of diagnostic systems, testing of algorithms of operational control or can be used for supporting the modeling of real processes occurring in similar systems.
\end{abstract}

Key words: mining machinery, diagnostics and control, scraper conveyor, fault simulation and diagnosis

\section{INTRODUCTION}

Scraper conveyors are some of the most important machines that belong to the so-called three-machine mining systems (a shearer, a hydraulic support and a scraper conveyor) [1] in the mechanized underground mines (see Fig. 1). The current tendency of development of new, more advanced and more powerful scraper conveyors induces the necessity of evaluating the behavior of the whole machine as well as its particular subsystems in the operation conditions in order to prevent unwanted operation modes or machinery downtime. The most effective way of such evaluation is to perform continuous monitoring of operation parameters of a machine and, based on the collected data, develop appropriate models and diagnostic procedures. However, performing extended measurements is often limited due to extremely difficult operation conditions in the underground coal mines as well as difficulties in accessibility to various mechanisms and devices installed in a conveyor. Thus, the measurement data is often incomplete and insufficient for proper evaluation of behavior of a machine and detection of possible faults occurring during operation. One of the ways to overcome this problem is the development of mathematical models that imitate behavior of real scraper conveyors. This approach allows for testing various scenarios of operation modes of a conveyor, including the possibility of modeling operational faults, and predicting the behavior of a machine.

The development of such models has several farreaching goals. Besides the possibility of simulating various operation scenarios and faulty conditions such a model can be successfully applied as a tool for designing new operation processes as well as a tool for the model-based diagnostics, where signals measured on a conveyor are compared to simulated signals in order to generate residuals. Then, residuals can be used for fault detection and isolation. As a further effect, the model developed can be implemented as a part of control algorithms that can be used for automation of diagnostic processes of conveyors of such a type.

The development of models of machinery and other technical objects is a common practice in design of monitoring and diagnostic systems. One can mention several model-based simulators that were developed as a supporting tool for development of diagnostic methodology of systems and processes: simulator of an electro-pneumatic automatic actuator used as 


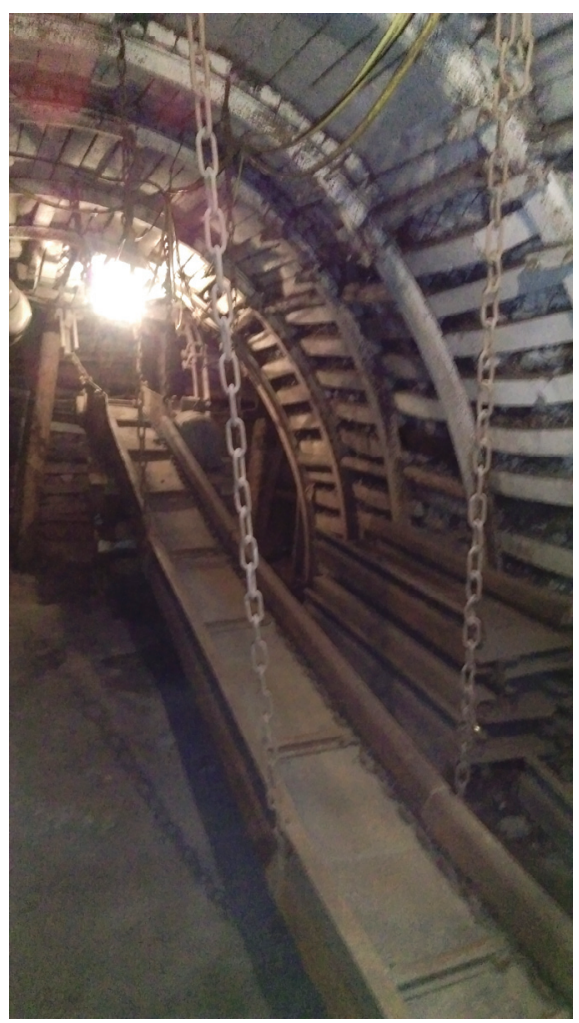

Fig. 1. The scraper conveyor in one of Polish mines (courtesy of A. Katunin)

a platform of diagnostic benchmarking within the DAMADICS project [2], simulator of a three-tank system used for fault detection and identification developed within the DiaSter system [3], simulator of a wind turbine developed within the fault tolerant control system [4], etc. Several systems were developed also for mining machinery, in particular for conveyors. One should pay attention to the models of conveyors developed by Dolipski and his team and described in numerous publications (see, e.g., [5], [6]). Besides these studies, the mathematical models of mining conveyors were developed by several other research teams, e.g., Mao et al. [7] developed a dynamic mathematical model of a scraper conveyor in order to investigate the chain behavior under certain operation conditions; while Eshin [8] developed the mathematical model (with Matlab ${ }^{\circledR} /$ Simulink $^{\circledR}$ implementation) of a scraper conveyor in order to test dynamic control algorithms.

The following study presents a mathematical model of scraper conveyor and its implementation in the Matlab ${ }^{\circledR} /$ Simulink ${ }^{\circledR}$ environment taking into consideration mechanical, electrical, measurement and control actuating systems that are originally installed on the scraper conveyors. The model generates three types of operation signals and can be launched in eight pre-defined scenarios typical of usual opera- tional conditions of an underground scraper conveyor. The simulator, implemented based on the mathematical model developed, provides a possibility of modeling various operational faults and taking into consideration a measurement noise generated by transducers. The parameterization of a model was performed based on the scraper conveyor of type JOY ${ }^{\circledR}$ BLS. The developed model and simulator will be ultimately applied for development of diagnostic and control algorithms dedicated to underground scraper conveyors.

\section{MATHEMATICAL MODEL OF A SCRAPER CONVEYOR}

As a basis of mathematical model the scraper conveyor of type JOY ${ }^{\circledR}$ BLS with three engines was assumed. The mathematical model of a scraper conveyor consists of the following submodels: model of a doubled main drive, model of auxiliary drive, model of mine breaker and contactor control, power supply model, model of equations of motion, model of masses, and model of motion resistance. These submodels are schematically presented in Fig. 2, and are described in the subsections below.

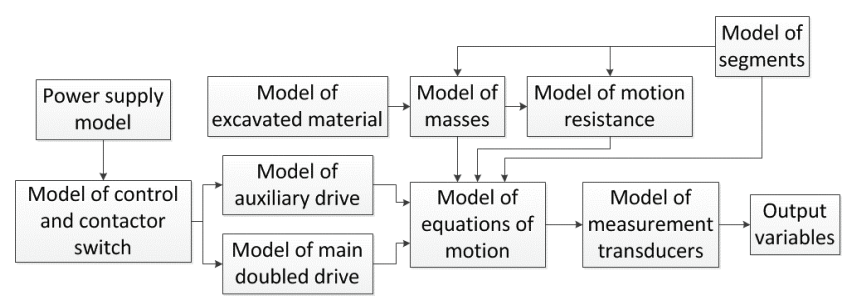

Fig. 2. The scheme of the assumed model of a scraper conveyor

\subsection{DRIVELINE MODEL}

The driveline model in the case under investigations consists of the models of main and auxiliary drives. The main drive is responsible for the transportation of excavated material located on the upper operating tendon. It consists of two explosion proof asynchronous cage motors, fluid coupling, gear and driving sprocket. The auxiliary drive is responsible for reducing the loading in the chain located on the driving sprocket. This drive consists of an explosion proof asynchronous cage motor, fluid coupling, gear and a turning sprocket.

The model of asynchronous cage motor can be described by the following relations [9] 


$$
\begin{gathered}
\underline{U}_{s}=R_{s} \underline{I}_{s}+\frac{d \underline{\Psi}_{s}}{d t}, \\
0=R_{r}^{\prime}{\underline{I^{\prime}}}_{r}+\frac{d \underline{\Psi}_{r}^{\prime}}{d t}-j p_{b} \Omega_{m} \underline{\Psi}_{r}^{\prime}, \\
\underline{\Psi}_{s}=L_{s} \underline{I}_{s}+L_{M}{\underline{I^{\prime}}}_{r}, \\
\underline{\Psi}_{r}^{\prime}=L_{r}^{\prime}{\underline{I^{\prime}}}_{r}+L_{M} \underline{I}_{s}, \\
\underline{I}_{s}=\frac{L_{r}^{\prime}}{W} \underline{\Psi}_{s}-\frac{L_{M}}{W} \underline{\Psi}_{r}^{\prime}, \\
\underline{I}_{r}^{\prime}=\frac{L_{s}}{W} \underline{\Psi}_{r}^{\prime}-\frac{L_{M}}{W} \underline{\Psi}_{s},
\end{gathered}
$$

where $W=L_{s} L_{r}^{\prime}-L_{M}^{2}$.

$$
\begin{aligned}
& M_{e}=\frac{3}{2} p_{b} \operatorname{Im}\left(\underline{\Psi}_{s}^{*} \underline{I}_{s}\right), \\
& \frac{d \Omega_{m}}{d t}=\frac{1}{J}\left(M_{e}-M_{o}\right),
\end{aligned}
$$

where $M_{e}$ - electromagnetic torque, $M_{o}$ - load torque, $J$ - moment of inertia, $p_{b}$ - number of pairs of magnetic poles, $\Omega_{m}$ - angular velocity of the motor, $\underline{U}_{s}$ - stator voltage space vector, $R_{s}$ - stator winding resistance, $R_{r}^{\prime}$ - rotor winding resistance relegated to the circuit of the stator, $\underline{I}_{s}$ - stator current space vector, $\underline{I}_{r}^{\prime}$ - the rotor current space vector relegated to the circuit of the stator, $L_{s}$ - inductance of stator windings, $L_{r}^{\prime}$ - rotor windings inductance relegated to the circuit of the stator, $L_{m}-$ magnetizing inductance, $\underline{\Psi}_{s}-$ the stator flux space vector, $\underline{\Psi}_{r}^{\prime}$ - space vector of the rotor flux brought to the circuit of the stator.

In the case of modeling the motor in the ClarkStanley coordinate system it is necessary to introduce the transformation of phase coordinates $a, b, c$ to the fixed coordinates associated with a stator $\alpha, \beta, 0$. In the case of absence of higher harmonics they can be described as [9]

$$
\begin{gathered}
k_{\alpha}=k_{a}, \\
k_{\beta}=\frac{k_{b}-k_{c}}{\sqrt{3}},
\end{gathered}
$$

where $k_{\alpha}, k_{\beta}$ are $\alpha$ and $\beta$ components, respectively, of the vector $k$ in a coordinate system associated with the stator, and $k_{a}, k_{b}, k_{c}$ are the phase components $a, b, c$ of the vector $k$; while in the case of presence of higher harmonics eqautions (9) and (10) take the form

$$
k_{\alpha}=\frac{2}{3}\left(k_{a}-\frac{k_{b}+k_{c}}{2}\right),
$$

$$
k_{\beta}=\frac{k_{b}-k_{c}}{\sqrt{3}} .
$$

Taking into consideration these relations and transforming the phase coordinates into the coordinates associated with a stator the relations (1)-(8) take the form

$$
\begin{gathered}
\underline{U}_{s}=U_{s \alpha}+j U_{s \beta}, \\
\underline{I}_{s}=I_{s \alpha}+j I_{s \beta}, \\
\underline{\Psi}_{s}=\Psi_{s \alpha}+j \Psi_{s \beta}, \\
\underline{I}_{r}^{\prime}=I_{r \alpha}+j I_{r \beta}, \\
\underline{\Psi}_{r}{ }_{r}=\Psi_{r \alpha}+j \Psi_{r \beta},
\end{gathered}
$$

$$
\frac{d \Omega_{m}}{d t}=\frac{1}{J}\left[\frac{3}{2} p_{b}\left(\Psi_{s \alpha} I_{s \beta}-\Psi_{s \beta} I_{s \alpha}\right)-M_{o}\right] .
$$

The model of a fluid coupling can be described by the following relation [9]

$$
M_{s}=\varphi_{s} \cdot \alpha_{s}+\varphi_{s}^{3} \cdot \beta_{s}+\tau_{s} \cdot\left(\alpha_{s}+3 \cdot \varphi_{s}^{2} \cdot \beta_{s}\right) \cdot \frac{d \varphi_{s}}{d t},
$$

where $M_{s}$ is the coupling torque, $\varphi_{s}$ - angle of rotation of the coupling, $\alpha_{s}, \beta_{s}-$ stiffness coeeficients of participation of linear and non-linear components, $\tau_{s}$ - delay constraint of a fluid coupling.

A gear can be defined by several equations related to the particular components of a torque. Since the torque on the motors is one of the signals analyzed on the output of the model it is necessary to introduce the relations which will allow the torque to be determined.

The gear ratio is described by the relation [9]

$$
i=\frac{\omega_{o}}{\omega_{i}}=\frac{n_{0}}{n_{i}},
$$

where $i$ is the gear ratio, $\omega_{i}, \omega_{o}$ are the angular velocities on the input and otput of a gear, respectively. The torque losses which should be considered in the model can be determined based on the following relationship [9]

$$
\Delta M_{p}=\frac{M_{b}}{\omega_{o} \cdot \eta_{p}} \cdot\left(1-\eta_{p}\right),
$$

where $\Delta M_{p}$ - torque losses of a gear, $M_{b}$ - torque of the drive drum, and $\eta_{p}$ - gear efficiency. The engine torque relegated to the drive shaft of the driving sprocket can be determined based on the following relationship [10]

$$
M_{n}=\left[M_{s}-\Delta M_{p}\right] \cdot \eta_{n} \cdot i,
$$


where $\eta_{n}=\eta_{s} \cdot \eta_{p}, M_{n}$ - drive torque of the engine relegated to the drive shaft sprocket, and $\eta_{n}, \eta_{s}$ - efficiency of the drive and coupling, respectively. The torque on the driving spocket can be calculated as follows

$$
M_{g n}=M_{n 1}+M_{n 2} .
$$

In the case of auxiliary drive relation (23) takes the form

$$
M_{g p}=M_{n p} .
$$

The output torque can be described as [11]

$$
M_{w y}=M_{s}+J_{s} \frac{d \omega_{s}}{d t},
$$

where $M_{w y}$ - the output torque of the drive drum, $M_{s}$ - elastic torque, $J_{s}$ - moment of inertia of the motor, $\omega_{s}$ - the angular velocity of the motor. The elastic torque is described by

$$
\begin{gathered}
M_{s}=c \varphi+\mu \frac{d \varphi}{d t}, \\
M_{s}=M_{w y}+J_{m} \frac{d \omega_{m}}{d t},
\end{gathered}
$$

where $\mu$ - damping coefficient, $c$ - elasticity coefficient, $J_{m}$ - moment of inertia of the mechanism, $\varphi$ - angle of rotation, $\omega_{m}$ - angular velocity of the mechanism. The instantaneous value of the angle of rotation is described with relations

$$
\begin{gathered}
\varphi=\alpha_{s}-\alpha_{m}, \\
\frac{d \varphi}{d t}=\omega_{s}-\omega_{m},
\end{gathered}
$$

where $\alpha_{s}$ - angle of the motor shaft, $\alpha_{m}$ - angle of the mechanism shaft.

\subsection{POWER SUPPLY MODEL}

The mathematical model of the power supply network consists of equations describing voltage of each of the supplying phases [12]

$$
\begin{gathered}
U_{a}=U_{m} \cdot(\sin \omega t), \\
U_{b}=U_{m} \cdot\left(\sin \omega t+\frac{2}{3} \pi\right), \\
U_{c}=U_{m} \cdot\left(\sin \omega t-\frac{2}{3} \pi\right),
\end{gathered}
$$

where $U_{a}, U_{b}, U_{c}$ - voltage of the phases, $U_{m}$ - maximum value of the supply voltage, $\omega$ - supply voltage ripple, $t$ - time. In the case of the mine power supply network, a network system with isolated neutral point IT is used.

\subsection{MODEL OF MINE BREAKER AND CONTACTOR CONTROL}

The control system and contactor switch controlled by this system are the additional mathematical models that allow modeling of different operational states (run-up, run-down, tripping, shutdown, emergency shutdown) of a conveyor. In real systems, control is carried out in the following configurations: local and remote control. A control voltage signal is described by the relation

$$
U_{s}=\left\{\begin{array}{lll}
0 & \text { for } & \text { 'off', } \\
1 & \text { for } & \text { 'on'. }
\end{array}\right.
$$

In the case of switch contactor the following devices are modeled most often: main contactor, trigger circuit, short circuit protection, overloading protection, and asymmetric protection.

The model of main contactor is described by

$$
U_{s g}=\left\{\begin{array}{ccc}
0 & \text { when } & U_{w y a}, U_{w y b}, U_{w y c}=0, \\
1 & \text { when } & U_{w y a}, U_{w y b}, U_{w y c}=U_{w e a}, U_{w e b}, U_{w e c},
\end{array}\right.
$$

where $U_{w e x}, U_{w y x}$ - input and output voltage of phase $x$, and $U_{s g}-$ control voltage of main contactor.

A short-circuit protection model is described by the following relation

$$
U_{s g}=\left\{\begin{array}{cccc}
0 & \text { for } & I_{w y a} & \geq I_{z n}, \\
0 & \text { for } & I_{w y b} & \geq I_{z n}, \\
0 & \text { for } & I_{w y c} & \geq I_{z n}, \\
1 & \text { for } & I_{w y a}, I_{w y b}, I_{w y c} & <I_{z n},
\end{array}\right.
$$

where $I_{w y x}$ - output current of phase $x, I_{z n}$ - current of a short-circuit protection. by

The model of overloading protection is described

$$
U_{s g}= \begin{cases}0 & \text { for } I_{w y a}, I_{w y b}, I_{w y c} \geq I_{p n} \text { and } t_{p n} \geq t_{p n u}, \\ 1 & \text { for } I_{w y a}, I_{w y b}, I_{w y c}<I_{p n} \text { and } t_{p n}<t_{p n u}\end{cases}
$$

where $I_{p n}$ - overcurrent (thermal) protection, $t_{p n}-$ response time of protection, $t_{p n u}-$ overloading time. 


\subsection{EQUATIONS OF MOTION}

In order to represent equations of motion of scraper conveyor, a discretized model of particular subsystems that describe motion of scrapers was assumed. The following four subsystems were considered: lower tendon (segment 1), turning sprocket with auxiliary drive (segment 2), upper (operating) tendon (segment 3), and driving sprocket (segment 4). A scheme of the discretized model is presented in Fig. 3. The modelling procedure assumes two approaches: complex and simplified one. The complex approach assumes replacement of parts of scraper chain by a system of differential equations. This approach is used by Dolipski and his team. The equations of motion for a scraper conveyor using this approach can be found, e.g., in his book [5]. where $W_{x x(j)}$ - motion resistance of the $j$-th segment of the conveyor, $a_{x x(j)}, b_{x x(j)}, c_{x x(j)}, d_{x x(j)}-$ coefficients of approximation of external friction (in the case of linear approximation $b, c, d$ equal 0$), \gamma-$ slope of a segment $L / j$.

\subsection{MODEL OF MASSES AND LOADING OF EXCAVATED MATERIAL}

The model of masses of an operating tendon is described by [5]

$$
m_{x x(j)}=\left(m_{k}+\frac{m_{z}}{2 p_{z}}+c_{u x x(j)} m_{u x x(j)}\right) L,
$$

where $m_{x x(j)}$ - mass of the $j$-th segment of conveyor, $m_{k}$ - unitary mass of chain, $m_{z}-$ mass of a scraper,

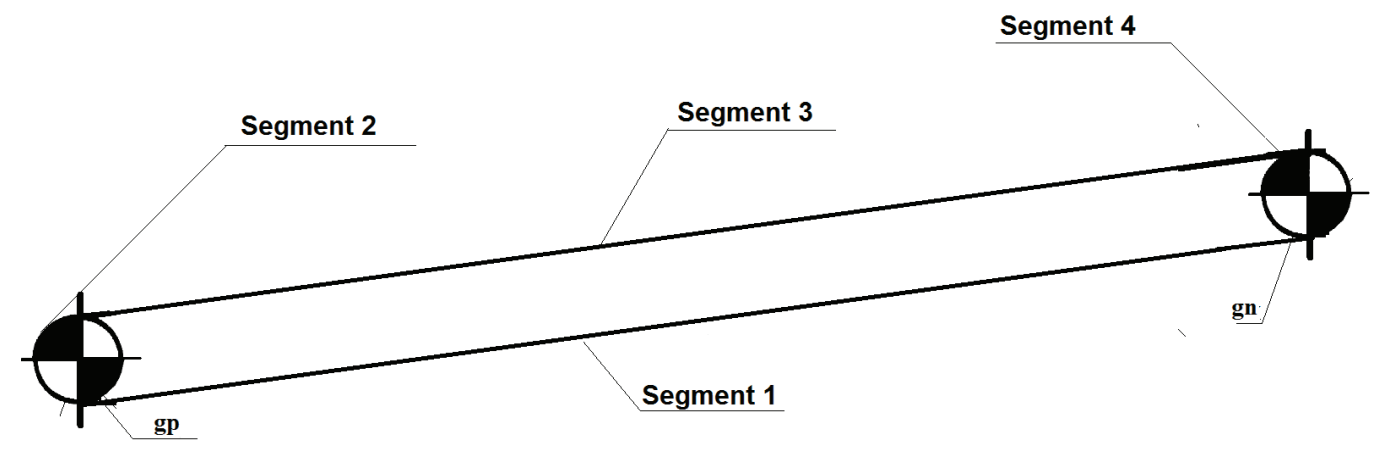

Fig. 3. Discretized model of a scraper conveyor

In the case of simplified approach, tendons of a conveyor are modelled as vibrating elements or vibrating elements with damping. Usually three types of models of tendons are used: elastic model, viscoelastic model, and standard (three-parameter) model. In this study, the simplest elastic model was assumed. This model is described by the following equations [13]

$$
\begin{array}{r}
\dot{V}(j) \cdot m(j) \cdot l(j)=F(j+1)-F(j)+P(j)-W(j) \cdot l(j), \\
\dot{F}(j+1) \cdot l(j)=A \cdot E \cdot[v(j+1)-v(j)] .
\end{array}
$$

\subsection{MOTION RESISTANCE}

The motion resistance, based on [5], can be described as follows:

$$
\begin{gathered}
W_{x x(j)}=9.81 \cdot m_{x x(j)} \\
\cdot\left[\left(a_{x x(j)}+b_{x x(j)} \cdot q_{x x(j)}^{1}+c_{x x(j)} \cdot q_{x x(j)}^{2}+d_{x x(j)} \cdot q_{x x(j)}^{3}\right),\right. \\
\left.\cdot \operatorname{sgn} q_{x x(j)} \cos \gamma_{x x(j)} \pm \sin \gamma_{x x(j)}\right],
\end{gathered}
$$

$p_{z}-$ pitch of bearing elements, $c_{u x x(j)}-$ mass coefficient for chain vibration, $m_{u x x(j)}$ - unitary mass of excavated material; while in the case of non-operating tendon equation (40) takes the form

$$
m_{x x(j)}=\left(m_{k}+\frac{m_{z}}{2 p_{z}}\right) L .
$$

In the case of sprockets the masses can be determined using the following equations

$$
m_{\text {gnnар }}(j)=\left(\left(m_{k}+\frac{m_{z}}{2 p_{z}}\right)+\frac{J_{\text {nпар }}(j)}{l(j) \cdot r_{\text {nnap }}^{2}(j)}\right) L,
$$

$$
m_{\text {gnap }}(j)=\left(\left(m_{k}+\frac{m_{z}}{2 p_{z}}\right)\right.
$$

$$
\left.+\frac{1}{l(j) \cdot r_{b}^{2}}\left\{\begin{array}{l}
J_{b}(j)+i_{p}^{2}(k) \cdot \eta_{p}(k) \\
+i_{p}^{2}(k+1) \cdot \eta_{p}(k+1) \cdot 0,5 \cdot J_{p}(k+1)
\end{array}\right\}\right) L,
$$

where $m_{\text {gnnap }}(j), m_{\text {gnap }}(j)$ - equivalent masses of the $j$-th segment of turning and driving sprockets, re- 
spectively, $r_{b}$ - radius of a sprocket, $i_{p}$ - gear ratio, $J_{b}$ - moment of inertia of a sprocket, $\eta_{p}$ - gear efficiency.

\subsection{MODEL OF TRANSDUCER}

The measurement transducers were considered in order to simulate real measurement conditions with measurement noise, quantization and sampling. Their parameters can be defined by the following relation

$$
\sigma_{e}=10 \exp \left(\log \sigma_{s}-0.05 \mathrm{SNR}\right),
$$

where $\sigma_{e}$ - variance of noise generator, $\sigma_{s}$ - the variance of the output signal, SNR - signal-to-noise ratio. It is also necessary to define: $p_{k}=2^{-N}$ - quantization level, $N$ - number of bits of a transducer, $t_{p}=1 / f_{p}$ - sampling time of a transducer, $f_{p}$ - sampling frequency of a transducer.

\section{SIMULATOR \\ OF A SCRAPER CONVEYOR AND ITS PARAMETERIZATION}

Based on the mathematical model presented in Section 2, a simulator of scraper conveyor was developed in the Matlab ${ }^{\mathbb{}} /$ Simulink $^{\circledR}$ environment. The model assumes the ability to simulate different operational scenarios of a conveyor, and the ability to simulate operational faults typical of scraper conveyors working underground. Similarly, as in the theoretical model the simulator consists of several subsystems responsible for various actions. The main block with a parameterization window, and internal modular structure of a simulator are presented in Figs. 4 and 5, respectively.

The parameterization of simulator was performed based on technical documentation of the modelled
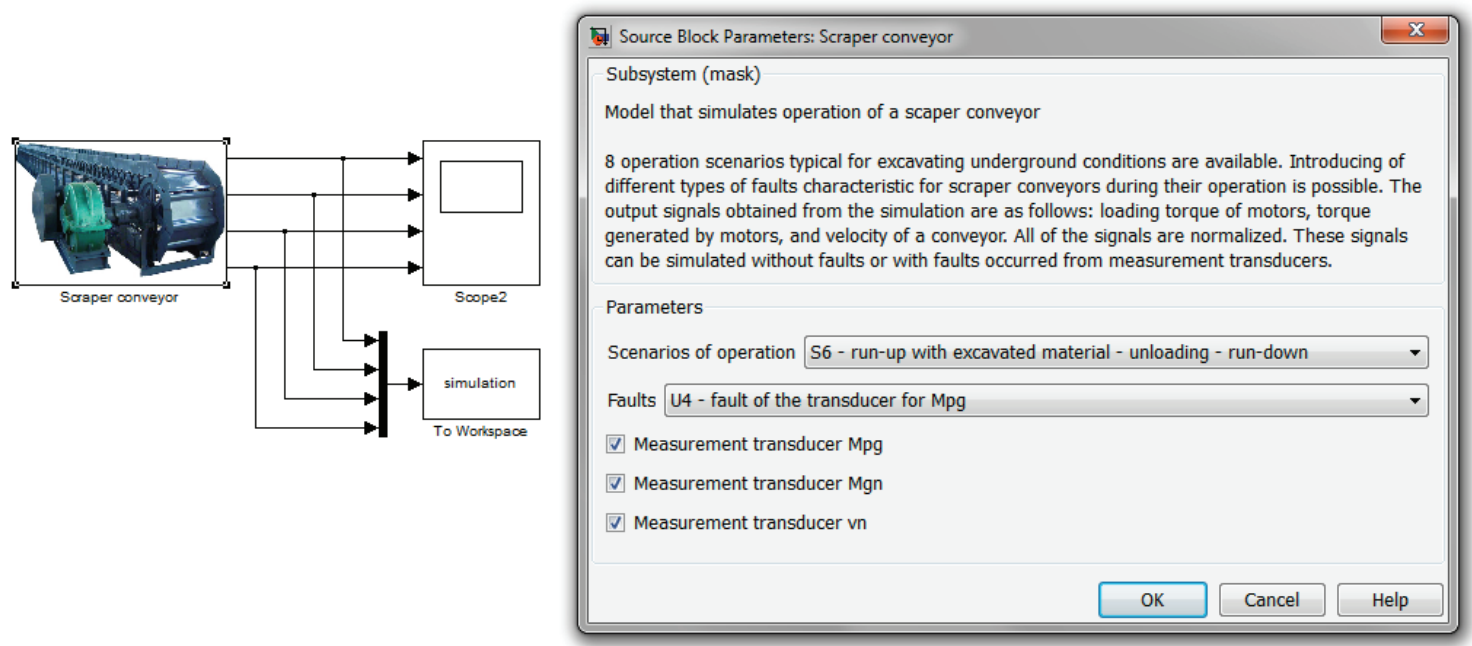

Fig. 4. The main block of the simulator of scraper conveyor and a parameterization window

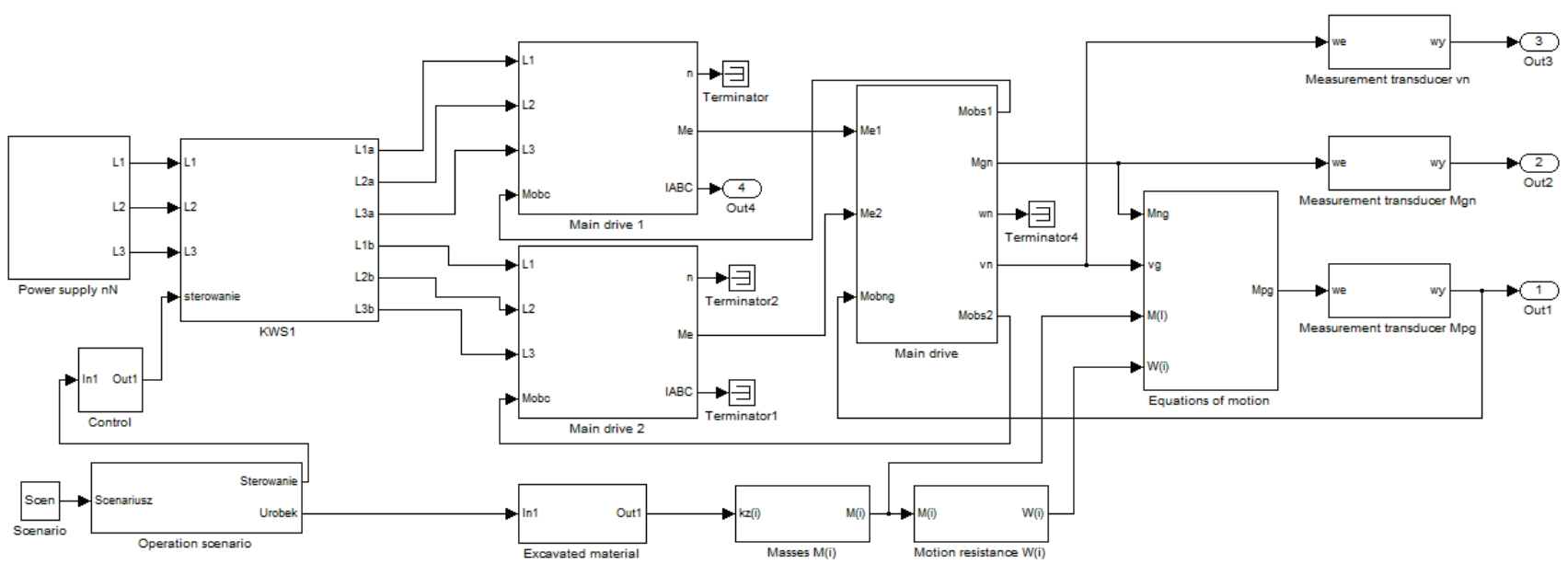

Fig. 5. Internal modular structure of a simulator of scraper conveyor 
conveyor, and data available in the literature [5], [14]. The main parameters of the modelled conveyor are presented in Table 1 . The operational parameters were determined theoretically or selected based on the experts' knowledge. The parameters for mass model and drive model are presented in Tables 2 and 3, respectively.

Table 1. Parameters of the conveyor JOY ${ }^{\circledR}$ BLS

\begin{tabular}{|l|c|c|c|}
\hline \multicolumn{1}{|c|}{ Parameter } & Symbol & Value & Unit \\
\hline Productivity & $Q_{p}$ & 2160 & $\mathrm{t} / \mathrm{h}$ \\
\hline $\begin{array}{l}\text { Chain type } \\
\text { (diam. } \times \text { pitch } \times \text { spacing) }\end{array}$ & - & $\phi 34 \times 126 \times 200$ & $\mathrm{~mm}$ \\
\hline $\begin{array}{l}\text { Diameter of the driving } \\
\text { sprocket }\end{array}$ & $D_{g n}$ & 0.2 & $\mathrm{~m}$ \\
\hline $\begin{array}{l}\text { Diameter of the turning } \\
\text { sprocket }\end{array}$ & $D_{g p}$ & 0.2 & $\mathrm{~m}$ \\
\hline Number of chains & $l_{c}$ & 2 & - \\
\hline Velocity of the conveyor & $v_{p}$ & 1.3 & $\mathrm{~m} / \mathrm{s}$ \\
\hline Length of the conveyor & $l_{p}$ & 250 & $\mathrm{~m}$ \\
\hline Gear ratio & $i$ & 13 & - \\
\hline Drive power & $P_{n}$ & $3 \times 250$ & $\mathrm{~kW}$ \\
\hline Supply voltage & $U_{n}$ & 500 & $\mathrm{~V}$ \\
\hline Sectional area of the chain & $A$ & $9.0792 \cdot 10^{-6}$ & $\mathrm{~m}{ }^{2}$ \\
\hline $\begin{array}{l}\text { Young's modulus } \\
\text { of the chain } \\
\text { (for steel) }\end{array}$ & $E$ & $2.1 \cdot 10^{11}$ & $\mathrm{~Pa}$ \\
\hline
\end{tabular}

Table 2. Parameters of mass model

\begin{tabular}{|l|c|c|c|}
\hline \multicolumn{1}{|c|}{ Parameter } & Symbol & Value & Unit \\
\hline Unitary mass of the chain & $m_{j t}$ & 22.7 & $\mathrm{~kg} / \mathrm{m}$ \\
\hline $\begin{array}{l}\text { Unitary mass of excavated } \\
\text { material }\end{array}$ & $m_{j u}$ & 461.54 & $\mathrm{~kg} / \mathrm{m}$ \\
\hline Mass of the scraper & $m_{z}$ & 35 & $\mathrm{~kg}$ \\
\hline $\begin{array}{l}\text { Mass coefficient for } \\
\text { chain vibration }\end{array}$ & $c_{x x}$ & 1 & - \\
\hline $\begin{array}{l}\text { Friction coefficient for } \\
\text { scrapers }\end{array}$ & $a$ & 3 & - \\
\hline $\begin{array}{l}\text { Moment of inertia of the } \\
\text { sprocket }\end{array}$ & $J_{g}$ & 2.5 & $\mathrm{~kg} \cdot \mathrm{m}^{2}$ \\
\hline
\end{tabular}

Table 3. Parameters of drive model

\begin{tabular}{|l|c|c|c|}
\hline \multicolumn{1}{|c|}{ Parameter } & Symbol & Value & Unit \\
\hline \multicolumn{1}{|c|}{1} & 2 & 3 & 4 \\
\hline Rated power & $P_{n}$ & 250 & $\mathrm{~kW}$ \\
\hline Rated voltage & $U_{n}$ & 500 & $\mathrm{kV}$ \\
\hline Rated current & $I_{n}$ & 268 & $\mathrm{~A}$ \\
\hline Rated torque & $M_{n}$ & 1286 & $\mathrm{Nm}$ \\
\hline Rated efficiency & $\eta_{n}$ & 95.7 & $\%$ \\
\hline Overload capability & $p_{m}$ & 2 & - \\
\hline Rated frequency & $f_{n}$ & 50 & $\mathrm{~Hz}$ \\
\hline Number of poles pairs & $p$ & 2 & - \\
\hline Starting torque & $M_{r}$ & 2829 & $\mathrm{Nm}$ \\
\hline
\end{tabular}

\begin{tabular}{|l|c|c|c|}
\hline \multicolumn{1}{|c|}{1} & 2 & 3 & 5 \\
\hline Starting current & $I_{r}$ & 1983 & $\mathrm{~A}$ \\
\hline Rated power coefficient & $\cos \varphi_{n}$ & 0.9 & - \\
\hline Total moment of inertia & $J_{C}$ & 3.46 & $\mathrm{~kg} \cdot \mathrm{m}^{2}$ \\
\hline $\begin{array}{l}\text { Moment of inertia } \\
\text { of the motor }\end{array}$ & $J_{S}$ & 2.46 & $\mathrm{~kg} \cdot \mathrm{m}^{2}$ \\
\hline Rated slip & $s_{n}$ & 0.01 & - \\
\hline Rated critical slip & $S_{k n}$ & 0.037 & - \\
\hline Rated critical torque & $M_{k n}$ & 2572 & $\mathrm{Nm}$ \\
\hline Rated ripple & $\omega_{s n}$ & 155.43 & $\mathrm{rad} / \mathrm{s}$ \\
\hline Stator resistance & $R_{s}$ & 0.18 & $\Omega$ \\
\hline Rotor resistance & $R_{r}^{\prime}$ & 0.181 & $\Omega$ \\
\hline Stator leakage reactance & $X_{S \sigma}$ & 0.0001 & $\mathrm{H}$ \\
\hline Rotor leakage reactance & $X_{r \sigma}^{\prime}$ & 0.0001 & $\mathrm{H}$ \\
\hline Magnetizing reactance & $L_{m}$ & 0.0149 & $\mathrm{H}$ \\
\hline Rated speed & $n_{n}$ & 1485 & $\mathrm{~min}{ }^{-1}$ \\
\hline Gear efficiency & $\eta_{p}$ & 94 & $\%$ \\
\hline Coupling efficiency & $H_{s}$ & 98 & $\%$ \\
\hline Rigidity coefficient & $c$ & 2100 & - \\
\hline Damping coefficient & $\mu$ & 0.1 & - \\
\hline $\begin{array}{l}\text { Moment of inertia of the } \\
\text { mechanism and the motor }\end{array}$ & $J_{m}, J_{s}$ & 0.8 & $\mathrm{~kg} \cdot \mathrm{m}^{2}$ \\
\hline $\begin{array}{l}\text { Moment of inertia } \\
\text { of scrapers and a chain }\end{array}$ & $J_{z l}$ & 81 & $\mathrm{~kg} \cdot \mathrm{m}^{2}$ \\
\hline
\end{tabular}

\section{SIMULATION OF OPERATION SCENARIOS AND FAULTS}

\subsection{SCENARIOS AND FAULTS}

The simulator of a scraper conveyor provides a possibility of simulating eight operating scenarios, which represent the characteristic considering the operations performed during work. A list of possible scenarios in the simulator is presented in Table 4. The loading of excavated material is modelled as a linear increase of the coefficient $k_{z}$ (when it equals 1 - a full rated loading is obtained).

At the output of the simulator three parameters, which characterize the operation of a conveyor, are generated: loading torque of motors $M_{p g}$, torque generated by motors $M_{g n}$, and velocity of a conveyor $v_{n}$. Depending on needs, the signals can be generated with and without taking into account interference from transducers.

The simulator provides a possibility of simulating six types of faults and the healthy condition (U0) of a conveyor. The types of the faults are presented in Table 5. 
Table 4. Possible scenarios in the simulator

\begin{tabular}{|c|l|}
\hline $\begin{array}{c}\text { Scenario } \\
\text { nomenclature }\end{array}$ & \multicolumn{1}{|c|}{ Description } \\
\hline S1 & idle run-up \\
\hline S2 & idle run-up and run-down \\
\hline S3 & idle run-up, loading, run-down \\
\hline S4 & idle run-up, loading, unloading, run-down \\
\hline S5 & run-up with excavated material \\
\hline S6 & $\begin{array}{l}\text { run-up with excavated material, unloading, } \\
\text { run-down }\end{array}$ \\
\hline S7 & run-up with loading of excavated material \\
\hline S8 & $\begin{array}{l}\text { run-up with loading of excavated material, } \\
\text { unloading, run-down }\end{array}$ \\
\hline
\end{tabular}

Table 5. Possible faults in the simulator

\begin{tabular}{|c|l|}
\hline $\begin{array}{c}\text { Fault } \\
\text { nomenclature }\end{array}$ & \multicolumn{1}{c|}{ Description } \\
\hline $\mathrm{U} 1$ & drop of the supply power \\
\hline $\mathrm{U} 2$ & dust pollution of the lower space of gutters \\
\hline $\mathrm{U} 3$ & overloading by excavated material \\
\hline $\mathrm{U} 4$ & fault of the transducer for $M_{p g}$ \\
\hline $\mathrm{U} 5$ & fault of the transducer for $M_{g n}$ \\
\hline $\mathrm{U} 6$ & fault of the transducer for $v_{n}$ \\
\hline
\end{tabular}

It is assumed that during a given simulation only one type of fault may occur. The faults were modeled based on the technical documentation of the modeled conveyor, literature survey [5], [15],
[16] and experts' knowledge. The fault U1 assumes a drop of the supply power by $19 \mathrm{~V}$; while the fault $\mathrm{U} 2$ assumes an increase of the friction coefficient $a$ by 0.5 with respect to its nominal value (see Table 2). The faults U1 and U2 can appear in every operational scenario. The fault U3 assumes increase of the unitary mass of excavated material by ca. $100 \mathrm{~kg} / \mathrm{m}$ with respect to its nominal value (see Table 2) and can appear only in scenarios that consider operation with excavated material (S3-S8). For the rest of scenarios (S1, S2), despite choosing such a type of fault, the simulation is performed similarly as for the healthy condition U0. The faults U4-U6 assume an increase in measurement noise by 50 times with respect to their nominal values. These types of faults can be simulated only when the modes of particular transducer simulated signals are turned on.

\subsection{SIMULATION AND COMPARATIVE STUDIES}

The simulations were performed for all possible scenarios. The time of simulation was set to $40 \mathrm{~s}$, which allows all significant changes in simulated signals to be observed. The resulting signals for selected scenarios for the healthy condition of a conveyor without taking into consideration measurement noise are presented in Figs. 6-8. In the context of diagnostics all of the process signals considered were normalized.
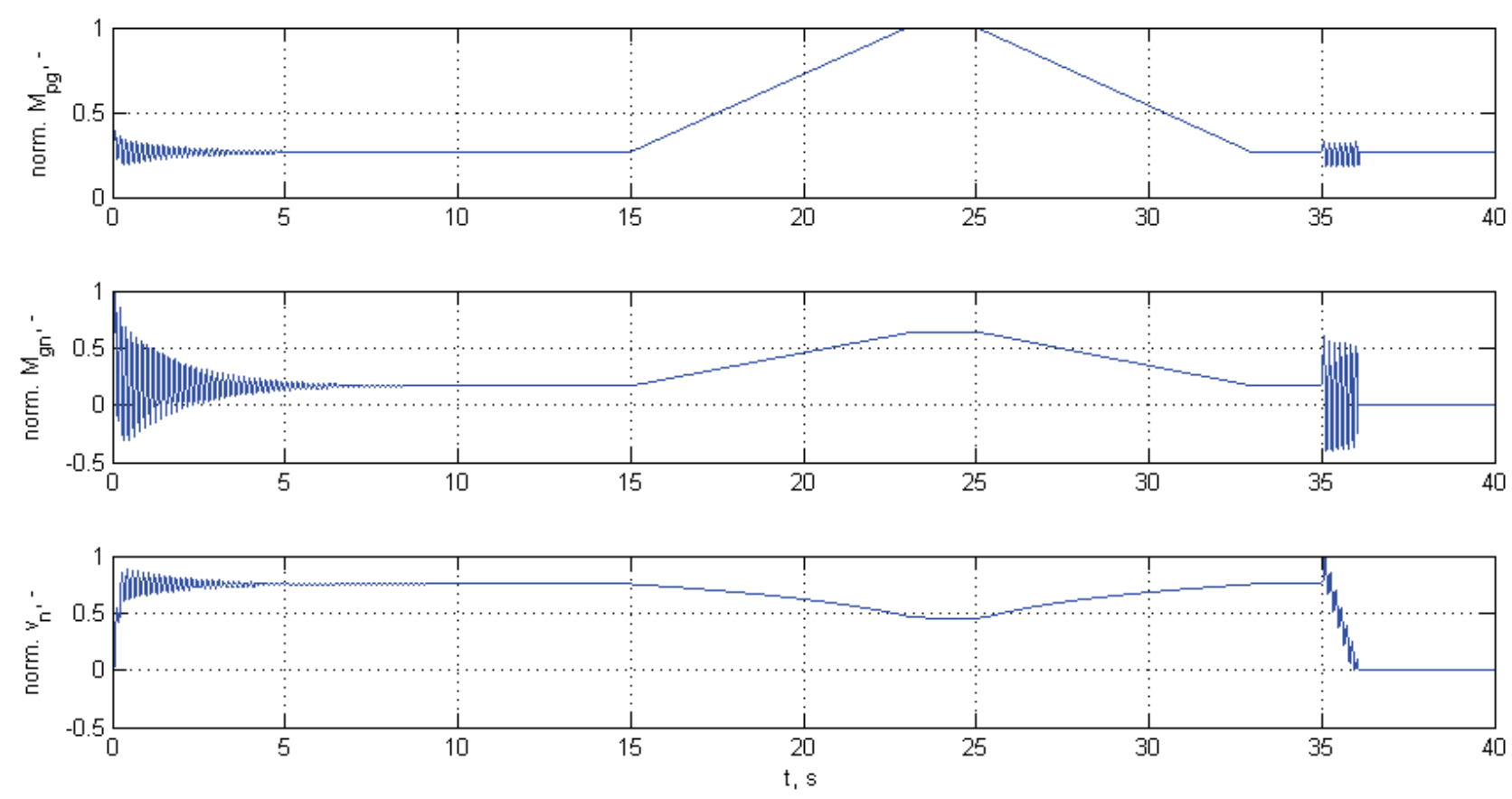

Fig. 6. Results of simulation following the scenario: idle run-up, loading, unloading, run-down (S4) 

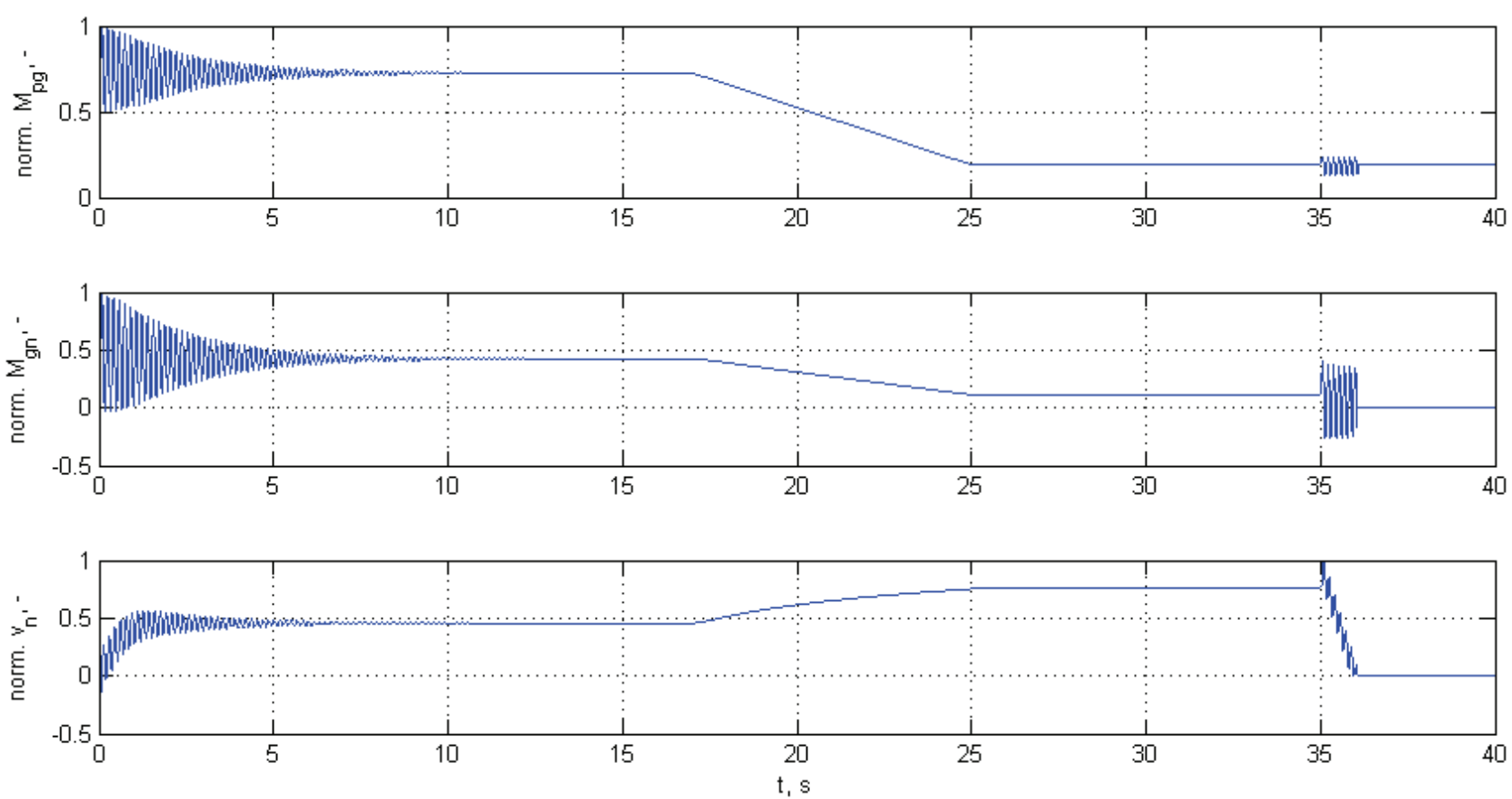

Fig. 7. Results of simulation following the scenario: run-up with excavated material, unloading, run-down (S6)
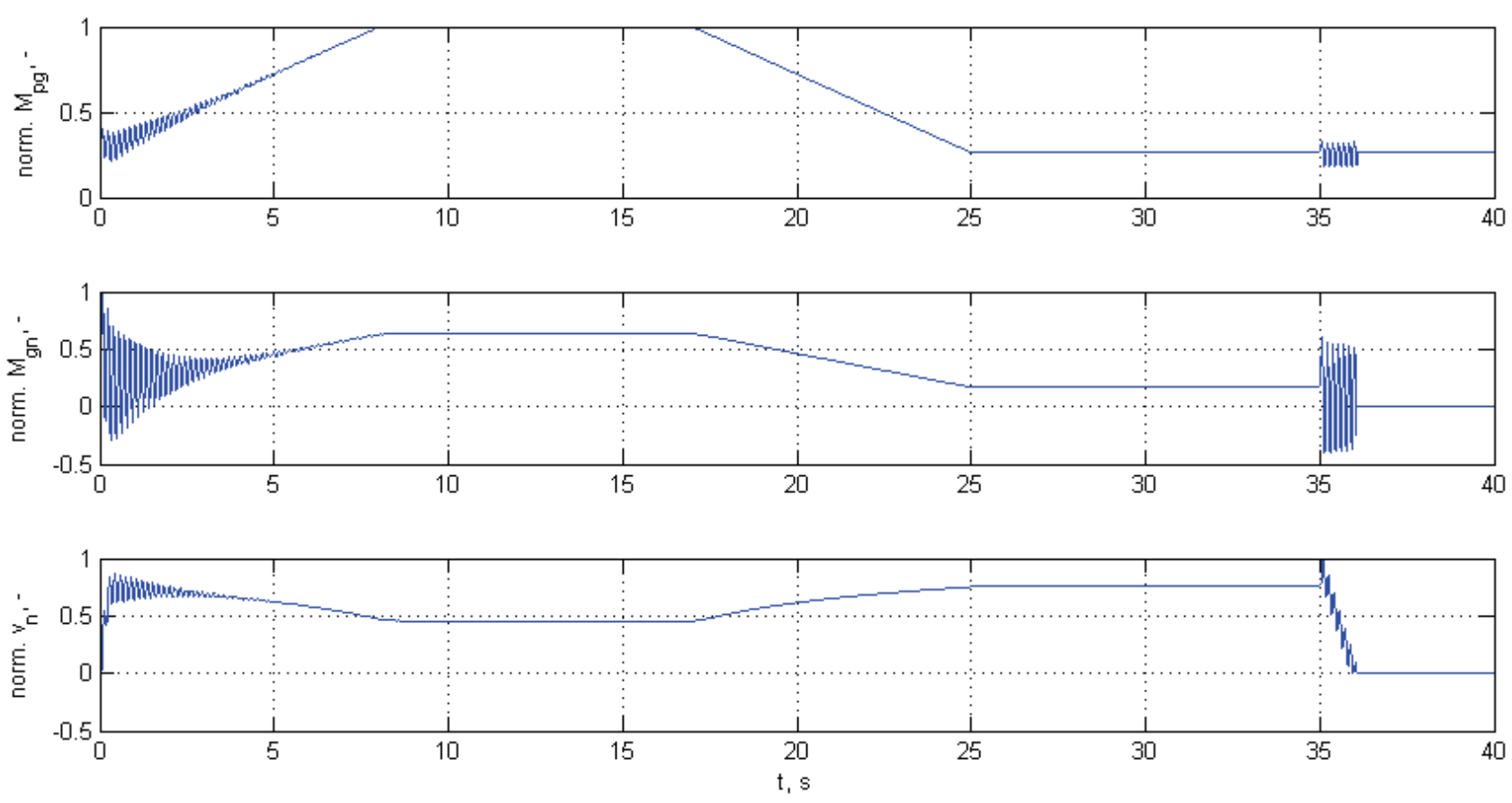

Fig. 8. Results of simulation following the scenario: run-up with loading of excavated material, unloading, run-down (S8)

From the waveforms presented in Figs. 6-8, one can observe significant variability in operation conditions which is connected directly with the opera- tions performed. For example, one can observe that run-up with excavated material requires much more power and the velocity of conveyor in significantly 
lower than in the case of idle run-up (cf. torque waveforms in Figs. 6 and 7). Much more favorable conditions can be observed during performing run-up with loading of excavated material, which does not overload conveyor motors. One can also observe dependences between simulated signals, e.g., the increase of torques causes a decrease in conveyor velocity.
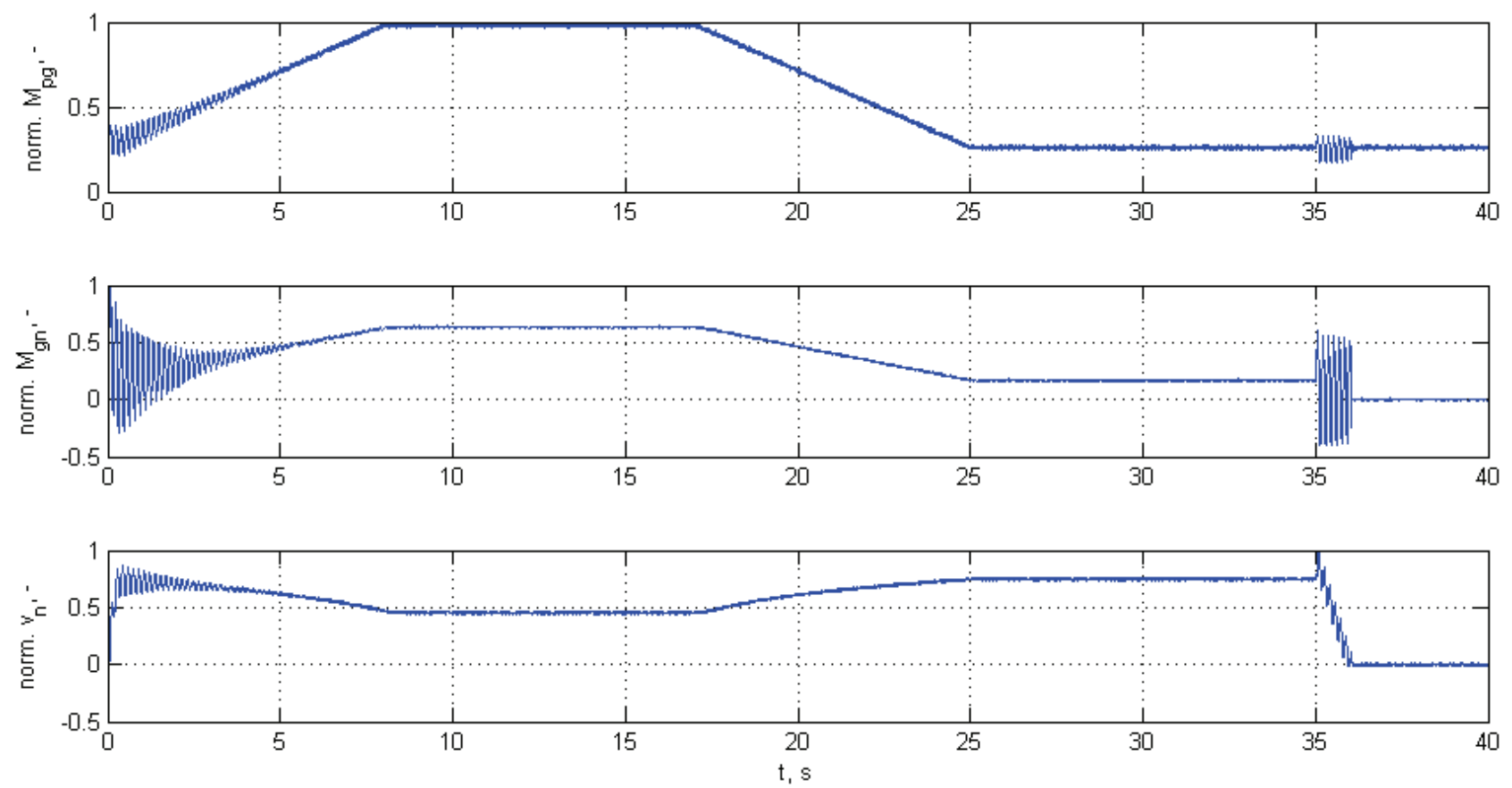

Fig. 9. Results of simulation following scenario S8 considering measurement noise generated by transducers
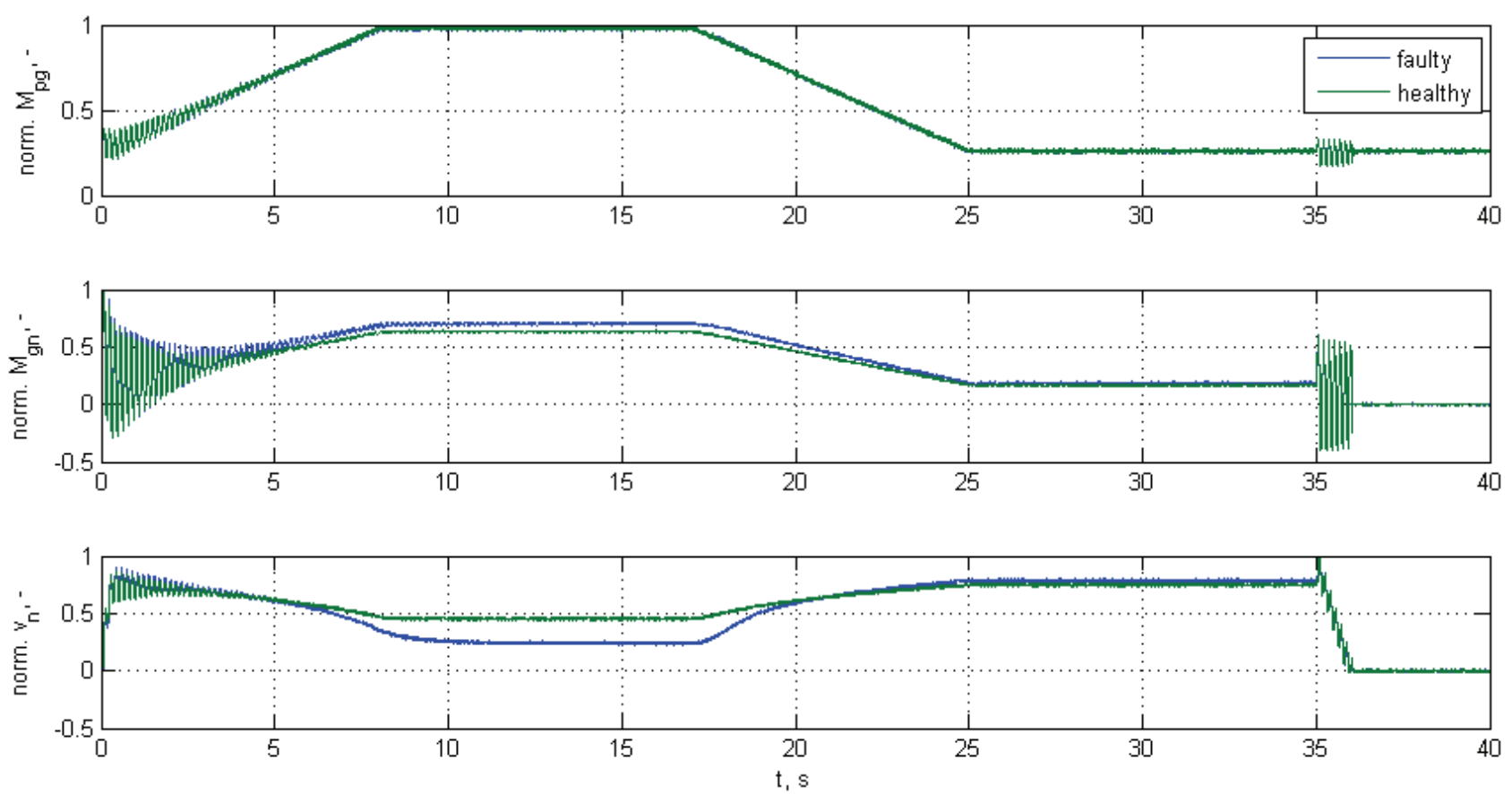

Fig. 10. Comparison of results of simulation following scenario S8 for healthy and faulty (U1) conditions 

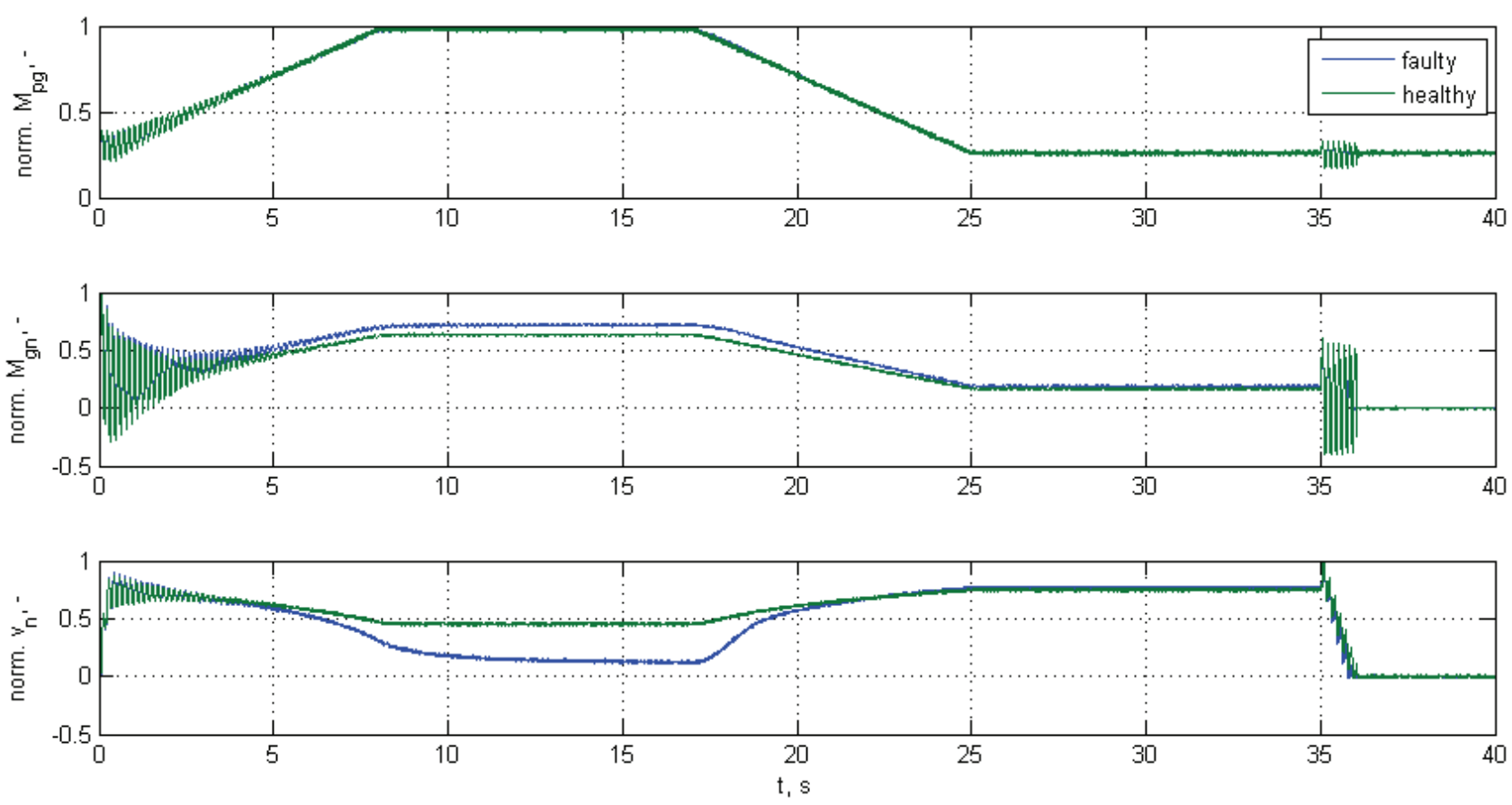

Fig. 11. Comparison of results of simulation following scenario S8 for healthy and faulty (U2) conditions
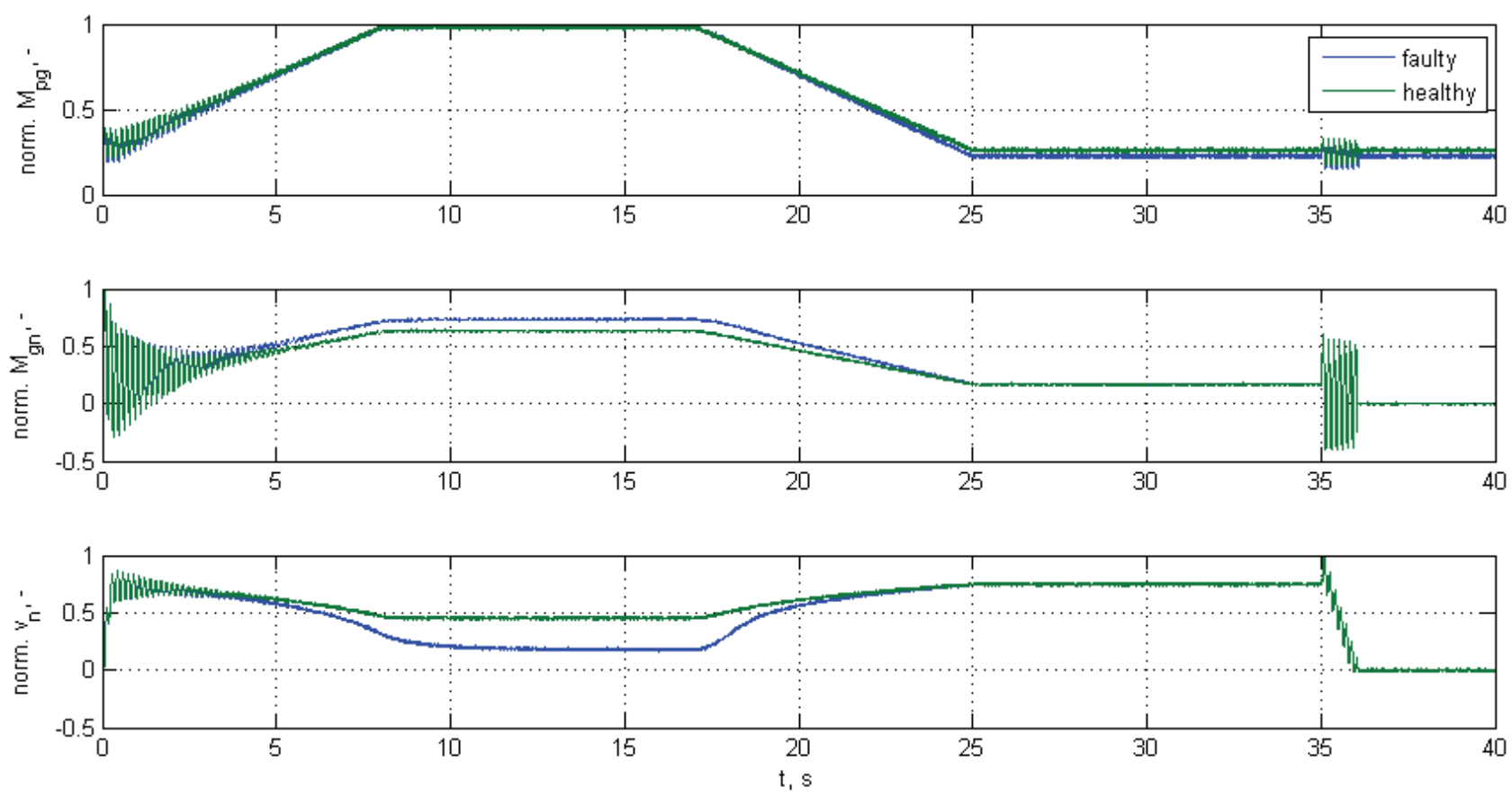

Fig. 12. Comparison of results of simulation following scenario S8 for healthy and faulty (U3) conditions

The influence of measurement noise for all simulated signals is shown in Fig. 9 based on scenario S8. This scenario was also selected to present faulty conditions with simulation of all modeled faults. The resulting signals for the faults $\mathrm{U} 1-\mathrm{U} 3$ are presented in Figs. 10-12, while the signals for the faults U4-U6 are presented in a common set of waveforms in Fig. 13, since in each case only one signal changes. 

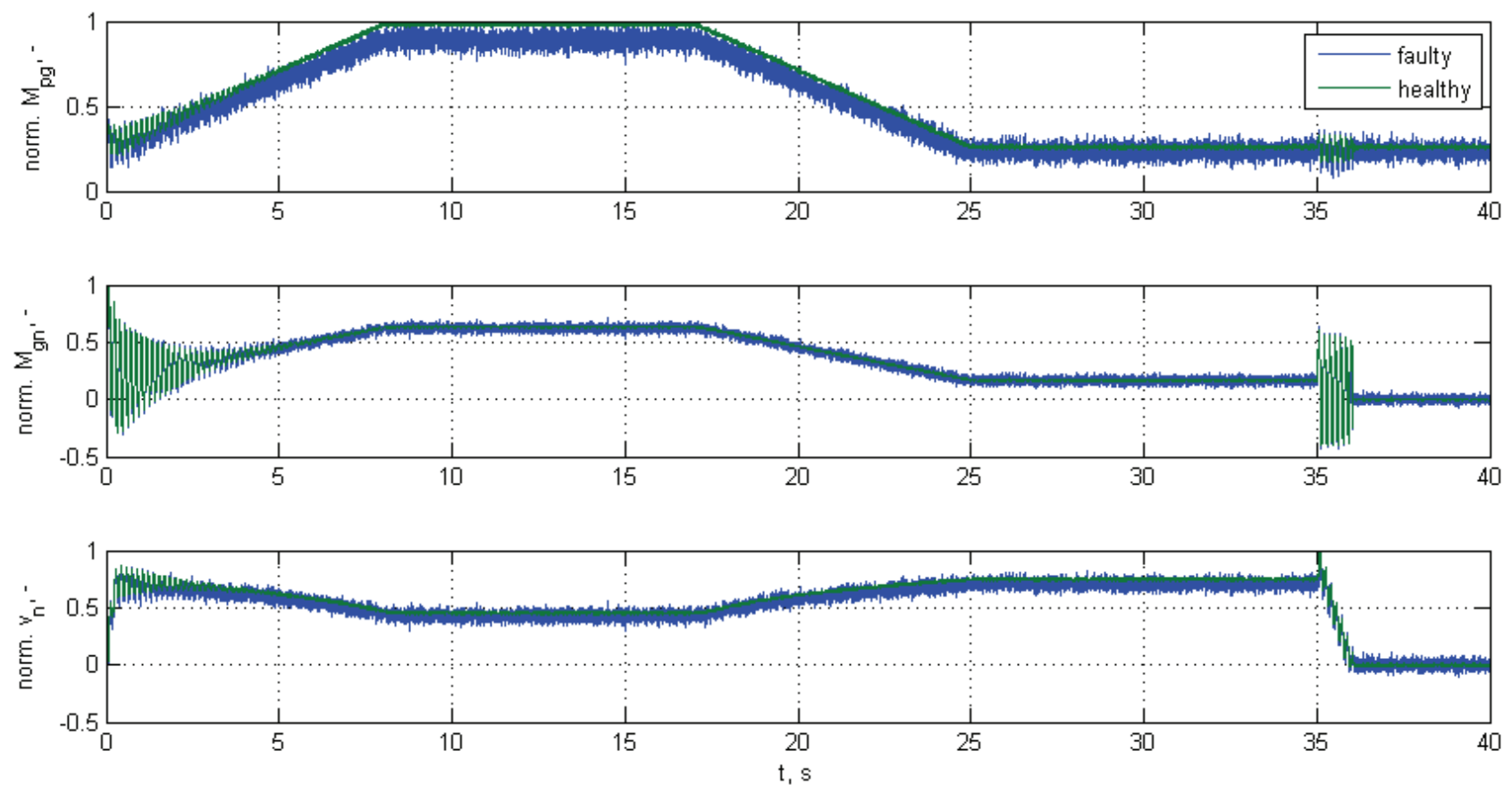

Fig. 13. Comparison of results of simulation following scenario S8 for healthy and faulty (U4-U6) conditions

Analyzing the results obtained for simulations of the faults, one can observe that the cases considered differ from each other, which introduces a basis for development of diagnostic tools for testing fault detection and isolation algorithms.

\section{CONCLUSIONS}

A mathematical model of scraper conveyor and a simulator based on this model was introduced and presented in this paper. The model was developed and parameterized according to the technical documentation of the $\mathrm{JOY}^{\circledR}$ BSL scraper conveyor, literature survey and experts' knowledge in order to simulate this machine in possibly accurate manner with respect to its real operational conditions. The model was implemented in the form of a simulator in the Matlab $^{\circledR} /$ Simulink ${ }^{\circledR}$ environment with a possibility of simulating typical operational scenarios and typical faults that may occur during operation of underground scraper conveyors. The simulations performed show that resulting signals obtained using the simulator developed are characterized by a good convergence with real measurement data. Following this, the proposed simulator can be applied in the development of appropriate diagnostic and control procedures that can be further applied to real underground machinery.
In further studies it is planned to tune up the model and simulator using real measurement data and advanced methods of artificial intelligence and soft computing.

\section{ACKNOWLEDGEMENTS}

The research presented in the paper was financed by the National Centre of Research and Development (Poland) within the framework of the project titled "An integrated shell decision support system for systems of monitoring processes, equipment and hazards" carried out in the path B of Applied Research Programme - grant No. PBS2/B9/20/2013.

\section{REFERENCES}

[1] FAN Q., WU Y., YU Z., Task coordination control modeling for coal machinery based on generalized partial global planning, Journal of Computational Information Systems, 2015, 11(2), 501-513.

[2] BARTYŚ M., PATton R., Syfert M., DE LAS Heras S., QueVEdo J., Introduction to the DAMADICS actuator FDI benchmark study, Control Engineering Practice, 2006, 14(6), 577-596.

[3] Korbicz J., Kościelny J.M. (eds.), Modeling, diagnostics and process control: implementation in the DiaSter System, Springer-Verlag, Berlin-Heidelberg, 2010.

[4] OdgaArd P.F., Stoustrup J., Kinnaert M., Fault tolerant control of wind turbines - a benchmark model, 7th IFAC Symposium on Fault Detection, Supervision and Safety of Technical Processes, Barcelona, Spain, 2011, 155-160. 
[5] Dolipski M., Dynamics of chain conveyors, The Silesian University of Technology Press, Gliwice, 1997, (in Polish).

[6] Dolipski M., Remiorz E., Sobota P., Determination of $d y$ namic loads of sprocket drum teeth and seats by means of a mathematical model of the longwall conveyor, Archives of Mining Sciences, 2012, 57(4), 1101-1119.

[7] Mao J., Shi J., Zhang D., Wei X., Dynamic modeling and simulation of heavy scraper conveyor, Journal of China Coal Society, 2008, 33(1), 103-106, (in Chinese).

[8] Eshin E.K., Modeling and management of dynamic state of conveyors, Vestnik KuzGTU, 2015, 108(2), 118-121, (in Russian).

[9] Tunia H., KaźMierowski M., Automation of converter drive, PWN, Warsaw, 1987, (in Polish).

[10] KAROLEWSKi B., LigOCKi P., Modelling of long belt conveyors, Eksploatacja i Niezawodność - Maintenance and Reliability, 2014, 16(2), 179-187.
[11] Szabat K., Control structures of electric drive systems with elastic joint, Scientific Papers of the Institute of Electrical Machines, Drives and Measurements of the Technical University of Wroclaw, 19(61), 2008, (in Polish).

[12] CichowsKa Z., PASKo M., Lectures on theoretical electrotechnics. Part II. Sinusoidal variable currents, 4th ed., The Silesian University of Technology Press, Gliwice, 2004, (in Polish).

[13] Ligocki P., KAROLEWSKI B., Investigation of influence of belt parameters on run-up waveforms of a conveyor, Scientific Papers of the Institute of Electrical Machines, Drives and Measurements of the Technical University of Wroclaw, 2004, 24(56), (in Polish).

[14] Plamitzer A.M., Electrical machines, 4th ed., WNT, Warsaw, 1976, (in Polish).

[15] Antoniak J., Scraper conveyors, Śląsk Publishing House, Katowice, 1968, (in Polish).

[16] Antoniak J., SuchoŃ J., Mining scraper conveyors, Śląsk Publishing House, Katowice, 1983, (in Polish). 